\title{
Improving Learner Motivation for EAP through TBLT in Tertiary Education - A Study on Higher National Diploma in Tourism Students at SLIATE
}

\author{
Udapadini Hewapathirana
}

${ }^{1}$ Sri Lanka Institute of Advanced Technological Education (SLIATE), Kappetipola Mawatha, Kandy.

\begin{abstract}
Improving the standards of English among the Sri Lankan tertiary level learners is quite a challenge for both the teachers and learners due to diverse issues such as lack of learner motivation, monotonous syllabi and the non-applicability of curriculum. The primary focus of this research was to address these issues and develop an approach using the Task Based Language Teaching method for tertiary level students who are following the Higher National Diploma in Tourism and Hospitality Management (HNDTHM) at Sri Lanka Institute of Advanced Technological Education (SLIATE). It was expected that this new approach would improve the learners' positive attitudes towards learning the language especially in an EAP scenario. Qualitative research method was executed where data was collected through 20 interviews conducted by the researcher to gather primary data. Finally it was comprehended that capitalizing on peer interactive learning and on tasks which are applicable to their professional scenarios motivate the learner. Further when the learners' oral communicative skills are much focused than the skill of writing and reading, the level of motivation was high among these learners. Therefore it was concluded that the use of TBLT is highly appropriate in motivating the learner for EAP at tertiary level.
\end{abstract}

Keywords: Improving, Motivation, Tertiary, TBLT, EAP

\section{Introduction}

The field of EAP started to develop in Sri Lanka about two decades ago, as many of the state university faculties decided to offer their degree programmes only in English medium. This tendency was taken up by SLIATE in the last decade and by now all the Higher National Diplomas conducted at SLIATE are offered only in English medium. In this manner, though EAP (English for Academic Purpose) has become an essential component in many tertiary level programmes, there is an aversion towards attending these classes especially coming from the learners in many government sponsored tertiary education institutes. Among the many and varied reasons causing this aversion, through this research the basic focus is to find out the co-relation between the applicability of the curriculum in par with the students' motivation. Throughout the empirical data collected through interviews with the EAP students, it was well observed that this antipathy towards EAP is backed by the monotonous teaching methodology and the curriculum to a very great extent.

Therefore the ultimate research objective is to find out the effectiveness of using TBLT for EAP students, through the research group of HNDTHM students. In fact the researcher has several objectives and basically it would be focused how effectively their communication skills can be improved through the Task based language teaching methodology. Further it will be also investigated whether this new methodology has improved the students' motivation towards the learning of the language. Further the research group was selected as HNDTHM students as these students specifically need the language English when they join with the field of tourism and Hospitality. Therefore it was assumed by the researcher that making these students' teaching methodology task based would ultimately make their leaning scenario more effective.

\section{Literature Survey}

Two decades ago EAP was another sub stream that continued to develop in par with ESP (English for specific purposes). Based on Widdowson (1997), it can be assumed that English, being used in this way, is always the language for specific purposes. Alcaraz-Varó (2000) rested his view on the opinion of Widdowson (1998: p. 04), who stated that 'all language use is specific in a sense, so that language serves a specific purpose wherever it is used. However, EAP as a pedagogic enterprise, is focused upon the specific language appropriate to the target discipline and activities. According to Strevens (1988) the rationale of EAP is based on following claims: being focused on the learners need, its relevance to the learner, its success in imparting learning, its cost effectiveness compared to General English. Therefore based on the concept of relevance, it was decided to develop the tasks so that the learners' would be much focused in learning.

According to Richards and Rodgers (1982) there are three distinctive levels within the systematic development of a teaching method as an approach, a design or a method. As it is stated, an 'Approach' is the most general level which refers to the theories of language and language learning, whereas design refers to a higher level where theory is converted to practical aspect such as syllabus and instructional materials. In fact through this research it will be finally analyzed how the application of new teaching and learning techniques as well as the catering of the learners' needs and making the learning process more meaningful and relevant to the students, could improve the standards of the EAP among the tertiary level students.

Firstly, in designing the new approach for these HNDTHM students the Task Based Language Teaching (TBLT) approach was selected as the most suitable as it is a very 


\section{International Journal of Science and Research (IJSR) \\ ISSN (Online): 2319-7064}

Index Copernicus Value (2015): 78.96 | Impact Factor (2015): 6.391

strong approach that empowers the learner with practical applicability of the language. According to Ellis (2003) TBLT is an approach that provides more opportunities for authentic communicative experiences for the learners. This approach was specifically selected because it provides the learner better opportunities, to engage in cognitive processes where they improve all four language skills. Further the main focus of TBLT is on meaning rather than on form and precisely it provides the learner many opportunities to engage in 'real-world language use' (Ellis, 2003). Therefore it is considered that through this approach the learners would get the maximum benefit to improve their language where they get the prospect of learning English for professional usage. Out of the many aspects of TBLT the special focus is being given for creative tasks through which they engage in language usage. Hence in curriculum development, the creative aspect is also considered as it makes the learner exposed to the language.

\section{Methodology}

\subsection{Place and time period and sampling technique}

The research was carried out at Kandy SLIATE and the research was executed for six months. During the first three weeks, a student population of 47 were interviewed using a structured interview to get their attitudes regarding the subject EAP and these students were representing the HNDTHM course. After interviewing these students and also by analyzing the students' attendance in the classes it was obvious that $67 \%$ of the student population shows a moderate to negative attitude regarding the subject EAP.

During the next seven weeks, the students were taught seven thematically based lessons using task based language teaching method. Afterwards, a selected sample of 20 students were interviewed again to see whether their attitudes have got changed after being exposed to this new teaching approach.

The used sampling technique was stratified random sampling where the target population was divided into sub categories and members were selected in proportion to represent both the genders. "A sampling procedure which gives equal chance to all possible samples each of size $n$ which can be drawn from a population of size $\mathrm{N}$, is called simple random sampling" (Kushwaha \& Kumar, 2009, p.25). Therefore it is believed that this sampling technique is the most suitable for this research as through this method different stratus of research sample group can be represented. The students were stratified according to the average of their $1^{\text {st }}$ and $2^{\text {nd }}$ assignment marks scored in the first semester. The student categorization was done in the following manner.

Table 1: Selection of the Sample

\begin{tabular}{|c|c|c|c|}
\hline & Marks range & $\begin{array}{c}\text { Selected number of } \\
\text { students }\end{array}$ & Male / Female \\
\hline A & $100 \%-80 \%$ & 04 & 01 males \\
& & & 03 female \\
\hline B & $79 \%-65 \%$ & 04 & 02 males \\
& & & 02 female \\
\hline C & $64 \%-50 \%$ & 06 & 03 males \\
\hline
\end{tabular}

\begin{tabular}{|l|l|l|l|}
\hline & & & \multicolumn{1}{|c|}{03 female } \\
\hline $\mathrm{D}$ & $49 \%-30 \%$ & 04 & 02 males \\
& & & 02 female \\
\hline $\mathrm{E}$ & $29 \%-00 \%$ & 02 & $\begin{array}{l}01 \text { males } \\
01 \text { female }\end{array}$ \\
\hline
\end{tabular}

In this manner $20,1^{\text {st }}$ year students who are following the Higher National Diploma in Hospitality Management were interviewed through a structured interview outline to gather information. In Range A, there was only one male student as only one male has scored $100 \%-80 \%$ and there were only two students who has scored marks in the range E. Therefore in order to balance the number it was decided to interview 06 students who have scored $64-50$ as the most number of students came under this range.

\subsection{Research design}

The Action research design was used in conducting the research as it allows the researcher to follow a characteristic cycle where an exploratory stance is adopted throughout several steps. This design was selected as it provides a comprehensible understanding of the problem and tries to develop a plan through which a set of interventional strategies are proposed and tested upon the validity. Through this research, the TBLT is being proposed as the intervention strategy in order to improve the students' positive attitudes related to language learning. The cyclic nature of this protocol really helps to understand the deeper sense of this problem and intervene in the most effective manner to solve the issue. Therefore action research design is considered to be the best possible research design that is most suitable for this research. The following chart clearly depicts the steps involved in the action research.

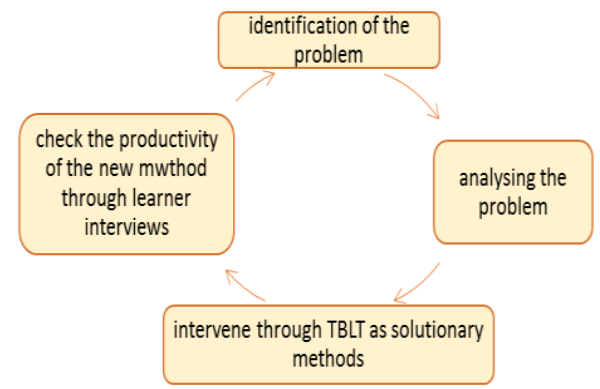

Figure 1: Action Research Cycle

The research was carried out with lessons, which were done using the TBLT approach. The lessons were developed focusing three different themes: cultural heritage in Sri Lanka, handling a guest as a tour guide and providing hotel based services to the customers. Along with these three topics seven lessons were prepared using the TBLT methodology. In fact the students were given the opportunity to have direct contacts with the foreign guest and based on this exposure they were supposed to prepare a report along with a CD that consists of a video clip as proof of their guide tour Based on the three themes which were mentioned above the following lessons were conducted. 


\section{International Journal of Science and Research (IJSR) \\ ISSN (Online): 2319-7064 \\ Index Copernicus Value (2015): 78.96 | Impact Factor (2015): 6.391}

Table 2: lessons based on TBLT approach

\begin{tabular}{|c|c|c|}
\hline & Theme & Lesson \\
\hline 01 & $\begin{array}{c}\text { Cultural } \\
\text { heritage }\end{array}$ & $\begin{array}{c}\text { Het the students to do a PowerPoint presentation } \\
\text { on a culturally important place }\end{array}$ \\
\cline { 3 - 4 } 02 & $\begin{array}{c}\text { Handling a } \\
\text { guest in a } \\
\text { tour guide }\end{array}$ & $\begin{array}{c}\text { Modals and polite use of spoken language } \\
03\end{array}$ \\
\cline { 3 - 3 } & $\begin{array}{c}\text { Hotel based } \\
\text { services for } \\
\text { the customers }\end{array}$ & Polite form of speech ( giving instruction, advices) \\
\cline { 3 - 4 } & & $\begin{array}{c}\text { Organizing a description/ changing topics } \\
\text { Handling customers at checking in and checking } \\
\text { out }\end{array}$ \\
\cline { 3 - 4 } & & $\begin{array}{c}\text { Providing hotel based facilities to the customers } \\
\text { (dealing with room reservations, housekeeping, } \\
\text { restaurant services) }\end{array}$ \\
\hline
\end{tabular}

\subsubsection{Interviews}

20 students were selected for the interviews using the stratified random sampling method to get their opinion regarding the different learning experiences that they faced with TBLT method. The following was the interview outline.

1) Which methodology is more interesting for you? The new teaching approach or the previous teaching approach? Why?

2) Which approach provides you more comprehensibility? Explain on your selection.

3) Do you think that the knowledge that you got from these lessons will be useful when you start your professional life?

4) What are the challenges that you felt with the new teaching approach?

5) Which teaching approach was more challenging for you in terms of workload?

6) What do you feel about the group activities that you had to do with the new approach?

7) Do you think that all four skills (reading, writing, speaking and reading) are important to your professional career?

8) Are they all reinforced through this new approach?

9) Do you think that this new approach motivates you better in learning the language? If so, why?

10)When you compare in between the two approaches which one suites your needs the best; the old method or the new approach?

The students were interviewed based on these questions and their responses were analyzed with reference to the exiting theories too. Through these questions the researcher tried to draw the connection between the learner motivation and the applicability of the learning material.

\section{Result \& Discussion}

\subsection{Results}

When interviewing the students it was clearly shown that the TBLT approach based activities are more affective in improving the students' four language skills rather than the previous teaching method. The data analysis given below clearly depicts this idea.
The first question of the interview was which approach out of the two was found to be more interesting. $98 \%$ of the students have answered to this question saying that TBLT approach is found to be more interesting than their previous learning experience. Irrespective of the score ranged groups, almost all the students have stated that TBLT approach based lessons are more interesting due to following factors.

About $64 \%$ of the students said that that can actively get engaged in the process of learning and therefore they feel really valued in the classroom for what they do. Further the majority of the students mentioned that they thoroughly enjoyed the group task where they had to guide a foreigner and also that it was highly exciting. They stated that this methodology is not monotonous. The learners have really liked the fact they can use the language for a practical purpose outside the classroom. Due to these reasons the majority of them said that the TBLT approach is far better than their previous learning experience.

Further the students also stated that this approach provides them with more comprehensibility because they get the chance to acquire first-hand experiences of the language usage. Further it was also mentioned that direct exposure to the on-the-job scenario provides them with much motivation to use the language accurately. When the language is being used in between the peers the learner does not worry about the accuracy much. Whereas in this scenario, where the learners were asked to directly deal with the foreigners, they focused much on the accurate use of the language.

The third question inquired about the applicability of the two approaches in relation to their expected employment ventures. In fact all students claimed that the applicability of the second approach is better than the first approaches as it provides the learner with many opportunities which are similar to that of their on-the-job required skills. For instance the learners usually get to guide tourists and engage in service providing situations in hotels. These circumstances are provided through the lesson and therefore all the participants directly stated that these lessons were highly motivating for them to learn the language especially as all the lesson topics are directly relevant to their on-the-job scenarios.

The fourth question inquired about the challenges that the students are facing with TBLT approach. The learners also mentioned that the direct exposure towards the language was sometimes causing too much of a challenge. For instance while they engaged in the convocations with the foreigners they faced difficulties in understanding and getting used to their accent. Mainly many students had got the chance to guide either the Chinese, Europeans or Indian tourists who were looking for budget traveling. Therefore especially when dealing with the European and Chinese guests, the students had found their accent difficult to understand.

The next question was related to the workload of the students. Out of the research population $74 \%$ of the students have claimed that TBLT approach was more challenging in terms of work load. For instance many of the students stated

\section{Volume 6 Issue 7, July 2017}

www.ijsr.net 


\section{International Journal of Science and Research (IJSR) \\ ISSN (Online): 2319-7064}

Index Copernicus Value (2015): 78.96 | Impact Factor (2015): 6.391

that having five subjects more to work on, all these tasks were demanding their time a lot as they were mostly group activity based. This situation has made them quite stressful especially in managing time and meeting up with deadlines.

The sixth question was based on how the students felt about the quality of the group activities that they engaged in. Many of the students said that they could enjoy the company of their group members and about $67 \%$ of the sample group commented saying that they could enjoy the activity with the peer interaction. Yet $14 \%$ of the students mentioned that they had problems in getting an equal contribution towards the task from all group members. In fact, the learners were provided with a team member contribution form at the beginning and the team leader was supposed to fill it and hand over at the end of the task. Therefore in most of the groups the members have contributed to their fullest capacity, whereas in some of the groups they have faced some difficulties.

The next two questions which were in connection with the reinforcement of all four language skills, the students mentioned that their all four skills got reinforced to some extend; yet they improved the spoken skill the most. Especially $58 \%$ claimed that both speaking and listening skills are reinforced a lot through this approach rather than reading and writing. Further they also expressed that since these two communication skills are the most important in their field, it is better that they got this opportunity to reinforce these skills.

Finally, out of the research population $98 \%$ students said that they really got motivated to learn the language through this new approach and they gave varied reasons for this motivation. Most of them said that they enjoyed it as these tasks were mostly group based and quite challenging as a novel experience of learning for them. Further they also mentioned that many of these tasks were based on their working experiences and this aspect really motivated them towards learning.

In fact all the students $(100 \%)$ claimed that TBLT approach is more suitable towards their learning process than the previous learning method as this new approach has provided them with interesting and interactive tasks which enthusiast them to learn the language more effectively. These data analysis can be connected along with the existing body of literature.

\subsection{Discussion}

According to Gardner and Lambert (1972) the motivation can be divided into two types as integrative and instrumental. Through this research the students' instrumental motivation will be improved by showing them the professional value of English language. This motivational factor would change their attitudes in a positive manner to improve the language. When the learners identify how useful the language can be in the professional scenario they would naturally get motivated to learn the language. This strategy is being used in this TBLT approach through this research.
As Lightbrown and Spada (2001, p. 33) have stated motivation to learn a second language is 'a complex phenomenon which can be defined in terms of two factors: learners' communicative needs and their attitudes towards the second language community'. When the learner needs to develop the language for communicative purposes, they would make a special attempt in improving the language. Secondly when the teacher can change the attitudes of the learner towards the language in a positive manner that can also contribute for the improvement of language teaching. In fact through this research an attempt is being made to change the learners' attitudes in a positive manner by showing them the applicability of the language in their professional life. Through the analysis of the data it is being proven that this attempt is a success.

The process of language learning can be accelerated through both intrinsic and extrinsic motivation. The intrinsic motivation is the mental satisfaction gained by the learner whereas the extrinsic motivation refers to an incentive activated by external factors such as good marks or grades. Through this research an attempt is being made to motivate the learners both intrinsically and extrinsically. For instance many of the students declared that they engaged in these tasks quite excitedly which is an evidence for intrinsic motivation. Moreover since these tasks were given as assignments they were motivated extrinsically too as grades were given to these assignments.

Further through this activity, the learner autonomy was created and once the learner becomes responsible in his/her own learning scenario, they tend to be more motivated. According to Nunan (2004) when the learner is in an autonomous learning environment, they feel much enthusiastic towards their learning material. In this manner the research has attempted and succeeded in improving the motivational factor of the students in a positive manner through a set of task based language teaching activities.

Further all these tasks were mainly reinforcing the peer interaction along with the learning process. According to Vygotsky (1978) as well as Walsh (2006), it is confirmed that the social interaction and context cannot be separated from the learning situation. This principle is being applied through these TBLT activities and according to many students' ideas they could enjoy these learning tasks especially since they are based on group activities. In this manner it is possible to connect the data collected through the research along with the existing literature related to this research topic.

\section{Conclusions}

Finally it can be concluded than the TBLT methodology has really motivated the learners towards learning English. It is recommended to make these tasks more profession oriented as it would really motivate the learners towards effective learning. Further it is also recommended to make these task more group oriented as group activities make the learning scenarios more enjoyable. Making the learning environment 


\section{International Journal of Science and Research (IJSR) \\ ISSN (Online): 2319-7064 \\ Index Copernicus Value (2015): 78.96 | Impact Factor (2015): 6.391}

more learner autonomous is another suggestion to make the EAP more successful.

Further providing the learners with manageable tasks as group activities would further motivate them towards the process on learning. TBLT is found to be motivating in tertiary level classes through the research findings. Yet it is also noticed that providing the learner with a manageable workload is also essential as learning experience should not be a burden for them. In fact, through managing the tasks in the most suitable way to suit the learners' need is the most successful approach in this learning scenario.

\section{Future Scope}

As this research was conducted through the technique of interviewing the researcher had to limit the number of participants in the sample group. Yet if it was carried out with a larger group of students who are not only from the first year, yet representing different academic years would be a way to develop the research further. Moreover developing tasks to suit other related fields like Management and Accountancy rather than limiting it to HNDTHM, would be another suggestion in improving the research further to suit the needs of diverse learner groups. In this manner the future scope of the research can be developed.

\section{References}

[1] J. F. Bobbitt, The curriculum, Houghton Mifflin, Boston, 1918.

[2] T. Dudley-Evans, \& M.J St. John, Developments in English for Specific Purpose,. Cambridge University Press, Cambridge, 1998.

[3] R. Ellis, Task-based language learning and teaching, Oxford University Press, Oxford, 2003.

[4] R. Ellis, \& H. Widdowson, Second Language Acquisition (Oxford Introduction to Language Study): Oxford University Press, Oxford, 1997.

[5] R. C. Gardner, \& W. E. Lambert, Attitudes and motivation in second language learning. Newbury House, Rowley, MA, 1972.

[6] T. Johns, \& T. Dudley-Evans, "An experiment in team teaching of overseas postgraduate students of transportation and plant biology", Team Teaching in ESP, ELT Documents 106, pp. 6-23. 1980.

[7] P. M. Lightbrown, \& N. Spada, "Factors affecting second language learning", In English language teaching in its social context, C.N. Candlin \& N. Mercer, (eds.), Routledge, London, 2001.

[8] D. Nelson, "English for Academic Purpose: Problem and Argument in Conceptualizing its Role in Academic," Hope Journal of Research, I (I), pp. 81-99. 2013.

[9] D. Nunan, Task Based Langugae Teaching, Cambridge University Press, Cambridge, 2004.

[10] J. C. Richards, \& T. S. Rodgers, "Method: Approach, Design, and Procedure," TESOL Quarterly, XVI (II), pp. 153-168, Retrieved 5 march 2017, from http://www.jstor.org/stable/3586789, 1982.
[11]P. Strevens, "ESP after twenty years: A re-appraisal." In EAP: State of the Art, M. Tickoo, (eds.), pp. 1-13, SEAMEO Regional Centre, Singapore, 1988.

[12]L.S. Vygotsky, Mind in Society, Harvard University Press. Harvard, 1978.

[13] S. Walsh, Investigating classroom discourse, Routledge, Oxon, 2006.

[14]H. Widdowson, Context, community and authentic language. TESOL Quarterly, XXXII (IV), pp. 705-716. 1998.

Volume 6 Issue 7, July 2017

www.ijsr.net

Licensed Under Creative Commons Attribution CC BY 